\title{
Explicit decay heat calculation in the nodal diffusion code DYN3D
}

\author{
Y. Bilodid ${ }^{1}$, E. Fridman ${ }^{1}$, D. Kotlyar ${ }^{2}$, E. Shwageraus ${ }^{3}$ \\ ${ }^{1}$ Helmholtz-Zentrum Dresden-Rossendorf, \\ Bautzner Landstraße 400, 01328 Dresden, Germany \\ Tel.: +493512602020 \\ Fax: +493512603299 \\ y.bilodid@hzdr.de \\ ${ }^{2}$ Georgia Institute of Technology, George W. Woodruff School, Nuclear and Radiological \\ Engineering, Atlanta, USA \\ ${ }^{3}$ Department of Engineering \\ University of Cambridge, CB2 1PZ Cambridge, United Kingdom
}

Keywords:

explicit decay heat calculation; microscopic depletion; DYN3D;

\section{Highlights}

- Microscopic cross-sections are pre-generated for each isotope and reaction type.

- Local concentrations of over 1000 nuclides are calculated using micro depletion.

- Time-dependent decay heat power is calculated by summing the isotopic decay heat contribution.

- The method is implemented in nodal code DYN3D and verified against Serpent 2.

\section{Abstract}

The residual radioactive decay heat plays an important role in some accident scenarios and, therefore, needs to be accurately calculated when performing accident analyses. The current reactor simulation codes used for accident analysis account for the residual decay heat by means of simplified models. Typically, these models rely on semi-empirical correlations which are defined over a limited range of burnup and fuel types. Therefore, the applicability of such correlations is limited and any deviation from the definition range may lead to high uncertainties, which is detrimental in evaluating safety margins. 
Reactor dynamic code DYN3D was originally developed for transient and accident analysis of LWRs. In DYN3D, the residual radioactive decay heat calculation is based on the German national standard DIN Norm 25463 model. The applicability of this model is limited to a low enriched uranium dioxide fuel for light water reactors.

This paper describes a new general decay heat calculation model implemented in DYN3D. The radioactive decay rate of each nuclide in each spatial node is calculated by recently implemented depletion module and the cumulative released heat is used to obtain the spatial distribution of the decay power for every time step. Such explicit approach is based on first principles and is free from approximations and, thus, can be applied to any reactor system (e.g. thermal and fast) and fuel type. The proposed method is verified through code-to-code comparison with the Serpent 2 Monte Carlo code results.

\section{Introduction}

Simulation of residual decay heat is important for the analysis of accident scenarios such as loss of coolant, main steam line break, station blackout, etc. The decay heat of spent fuel is also an important parameter for the design and analysis of facilities such as spent fuel storage pools, transportation systems, intermediate spent fuel storage and final disposal sites.

The residual decay heat is produced by a radioactive decay of nuclides which could be subdivided into two main groups (Tobias, 1980):

- fission products and nuclides produced by the neutron capture in fission products,

- actinides produced by the neutron capture in heavy metals.

Numerous methods of the decay heat calculation have been developed and mainly utilize the following two approaches or their combination:

1. The actual concentration of each relevant radioactive nuclide is calculated explicitly. Then, the decay heat is obtained as a sum over all nuclide decay rates multiplied by their corresponding energy released in each decay branch.

2. The time-dependent decay heat power produced by fission products of main fissile nuclides is described by a set of semi-empirical exponential fits (or lump Decay Heat Precursors). The decay constants and weight coefficients of each exponent are evaluated based on assumptions regarding reactor spectra (e.g. light water reactors - LWR) and operational power history (power pulse or long-term constant power operation). This data is tabulated in international (ISO 10645:1992) and national standards (DIN Norm 25463:1990; ANSI/ANS-5.1-2005). This approach is computationally cheap, but involves numerous 
assumptions (in addition to those made in standard curve fitting), since the user is required to provide the fission rates for each fissile nuclide as well as the actinides production rates which depend on the initial fuel composition, depletion history and particular operating conditions experienced by the fuel in the core.

The first approach is implemented in isotopic depletion code ORIGEN, as a part of SCALE package (Gauld et al., 2011), and Monte Carlo (MC) code Serpent (Leppänen et al., 2015). This approach requires detailed transport calculation of each fuel segment depletion history by a deterministic or MC code (Ilas et al., 2014), providing thermo-hydraulic feedback from a coupled code or in-core monitoring system, which makes it computationally expensive or requires significant depletion history simplifications.

The SNF code performs spent nuclear fuel analyses using isotopic concentrations from the 2dimensional lattice physics codes HELIOS (Wemple et al., 2017) or CASMO (Rhodes et al., 2006), providing power histories and burnups from a 3-dimensional core simulator (Børresen et al., 2008; Becker et al., 2009). This program combines nuclide concentrations calculation by solving selected decay chains with calculation of the decay heat produced by short-lived fission products using ANSI/ANS-5.1 decay heat standard.

Decay heat calculation based on standard curves is widely used in accident analysis of LWRs by such codes as RELAP5 (Sollima and Petrangeli, 2008), PARCS (Downar et al., 2010) and DYN3D (Rohde et al., 2016). However, if this methodology is applied to other fuel types or reactor systems, it introduces large uncertainties into the results (Shwageraus and Hejzlar, 2009).

This work proposes an explicit approach to calculate the decay heat power and describes its recent implementation in time-dependent nodal diffusion code DYN3D. This method relies on "first principles" - it utilizes detailed information on each nuclide concentration in the fuel and does not require approximations or assumptions regarding the initial fuel composition and its evolution with burnup.

In order to demonstrate the validity of the method, a code-to-code verification is performed against the Serpent code. The paper is structured as follows. Section 2 briefly presents the computer codes used in the study and describes the proposed decay heat calculation methodology. Section 3 describes the test case models and reports on the results of verification analysis. Section 4 summarizes the current work and presents conclusions. 


\section{DYN3D methodology}

\subsection{Brief code overview}

DYN3D is a 3D nodal reactor dynamic code developed at the Helmholtz-Zentrum Dresden-Rossendorf (HZDR), mainly for transients, but also for steady-state and fuel cycle analyses of LWR cores with hexagonal or square fuel assemblies (Rohde et al., 2016). DYN3D couples neutronic solution obtained using Nodal polynomial Expansion Method with internal thermal hydraulic and fuel rod behavior models. For the analysis of complicated transient and accident scenarios, where both 3D neutronics and thermal feedbacks from other plant components and safety systems play important role, DYN3D can be coupled with system codes such as ATHLET (Austregesilo et al., 2006; Grundmann et al., 1995) and RELAP5 (INL, 1998; Kozmenkov et al., 2001).

\subsection{Standard-based decay heat calculation}

DYN3D calculates node-wise decay heat power by applying the methodology described in the German normative document DIN Norm 25463 (DIN Norm 25463:1990; Grundmann et al., 2005). The fission products of four fissile isotopes U-235, U-238, Pu-239 and Pu-241 are divided into 24 groups, each having a characteristic decay constant. The decay heat power is calculated individually for each node taking into account the local power history. The contribution of each of the four fissile nuclides to total fission power and actinides buildup rates are pre-calculated by a lattice code and stored in an internal data structure. The current model for decay heat calculations is only applicable to UOX fuel in LWRs with a maximal initial enrichment of $4.1 \%$.

\subsection{DYN3D isotopic depletion solver}

The actual nuclide content in nuclear fuel depends on the node position in the reactor core and local operational history (i.e. history of the local temperatures, power and control rod insertion during the fuel burnup). To account for the actual local nodal nuclide content, a hybrid microscopic depletion method was recently developed and implemented in DYN3D (Bilodid et al., 2016).

DYN3D obtains the local nuclide content for each node at the end of each time step $\Delta t$ by solving the full set of Bateman equations in matrix form by computing the matrix exponential: 


$$
\mathbf{N}(t+\Delta t)=e^{\mathbf{A} \Delta t} \mathbf{N}(t)
$$

where $\mathbf{N}=\left[N_{1} \cdots N_{n}\right]$ is the local nuclide vector for a given time point. Operator $\mathbf{A}$ represents the transmutation matrix which is composed of the rates of neutron induced and decay reactions. The matrix exponential is computed using the Chebyshev Rational Approximation Method (CRAM) of $14^{\text {th }}$ order, which was found to be particularly efficient and accurate in fuel depletion problems (Pusa, 2011).

The number of considered nuclides and transmutation chains is not fixed in DYN3D but rather defined by the lattice code depletion calculation used to generate the homogenized cross sections data. More specifically, the dimensions of the decay and transmutation matrices in lattice code and DYN3D are identical. In this work, Serpent 2 was used to generate homogenized micro- and macroscopic cross section libraries for DYN3D (see section 2.5). In all the examined cases presented in this paper, 1200 nuclides were explicitly tracked by Serpent and DYN3D.

Currently, the depletion solver considers 5 types of neutron reactions: (n, $\gamma)$, (n,fission), $(n, 2 n), \quad(n, 3 n)$, and $(n, \alpha)$. Homogenized few-group microscopic cross sections for the considered reactions are generated by a lattice transport code along with homogenized fewgroup macroscopic cross sections (XS) and included in the few-group cross section library used by DYN3D. Energy-dependent fission yields are also stored in the internal DYN3D library of physical constants.

\subsection{Explicit decay heat model}

The fact that DYN3D tracks the full set of nuclides during all depletion and decay steps allows explicit calculations of important fuel characteristics such as decay heat in each node:

$$
P^{n}(t)=\sum_{i} N_{i}^{n}(t) \lambda_{i} q_{i}
$$

where

$P^{n}(t)$ - is the decay heat rate in node $n$ at time $t$;

$N_{i}^{n}(t)$ - is the concentration of nuclide $i$ in node $n$ at time $t$;

$\lambda_{i}$ and $q_{i}$ - are the decay constant and energy release per decay of the nuclide $i$, respectively. The sum in eq. (2) is over the entire set of nuclides (about 1200) in each node. The decay constants and energy released per decay of each nuclide were extracted from JEFF3.1 radioactive decay data file and included in an internal DYN3D library of physical constants. 
The fuel nuclide content of each node is calculated in DYN3D full core burnup calculation using the actual local fluxes and few-group microscopic cross sections which are dependent on the local operational parameters such as fuel temperature, moderator density, etc. The fewgroup homogenized microscopic cross sections are pre-calculated together with macroscopic diffusion parameters by the lattice transport code and stored in a cross section library which is parametrized against burnup and operational parameters. In this way, the detailed local operational history is taken into account explicitly and with low computational cost in comparison to a full core transport or Monte Carlo depletion calculation.

\subsection{Generation of the few-group macro- and microscopic cross sections}

This method relies on availability of few-group microscopic cross-sections and fission yields for more than 1000 nuclides. Typically, standard production lattice codes, such as CASMO or HELIOS, consider only few hundred neutronically important nuclides. Including more isotopes in the lattice level calculations has no impact on the neutronic results, since their neutronic importance is negligible (i.e. no or very low absorption cross-sections), however increases the computational requirements. Some nuclides however, may still contribute appreciably to decay heat while not being particularly important neutronically.

In this study, Monte Carlo code Serpent 2 was used to generate homogenized micro- and macroscopic cross sections required by DYN3D. The reason for this choice was a two-fold. Firstly, Serpent is capable of generating few-group homogenized macroscopic cross section data typically required by 3D core simulators (Leppänen et al., 2016). Moreover, starting from the version 2.1.29 Serpent was extended with a capability to conveniently generate also fewgroup microscopic cross sections and fission yield data.

Secondly, Serpent includes a built-in decay and depletion solver (Pusa and Leppänen, 2010) that tracks full decay and depletion chains without any approximations and, therefore, allowing for accurate prediction of irradiated fuel characteristics. In contrast to most depletion codes, these chains are not pre-defined but rather formed before any actual burnup calculation based on the initial burnable material content. The radioactive decay and fission yield data is obtained directly from ENDFB formatted radioactive decay and fission product yield data files which constitute part of the Serpent library.

One of the challenges associated with the use of Serpent is significant computational effort required for the generation of full cross section library. The current research has not included any possible optimization of depletion system such as combining of short-lived nuclides which 
have no influence on neutron balance into decay heat precursors (Huang et al., 2017). However, future analysis may focus on investigating such possibilities.

\section{Method verification}

\subsection{Verification Methodology}

In order to verify the new decay heat power calculation model of DYN3D, it was applied to several simple fuel pin or assembly test models which differ in material composition, operating history, and neutron spectra. The results obtained from DYN3D were compared to the corresponding reference Serpent solutions. The selection of infinite lattice models was driven by an intention to directly compare the depletion solvers of the two codes, by removing the effects of potential differences in transport solutions which could be observed when modeling larger heterogeneous problems with neutron leakage.

\subsection{PWR pin cell with UOX, MOX and TOX fuel}

To demonstrate the applicability of the proposed method to different fuel types, a depletion and decay heat production of uranium dioxide (UOX), uranium-plutonium mixed oxide (MOX) and thorium-plutonium mixed oxide (TOX) PWR fuel (Fridman and Kliem, 2011) are considered. Three fuel pin cells with reflective boundary conditions (see Fig. 1) and the same geometry, power and depletion conditions but different fuel compositions are modeled in Serpent and DYN3D. The fuel composition of UOX is uranium dioxide with $4.25 \mathrm{w} \%$ enrichment U-235; the Pu content in MOX and TOX fuels is equal to $7.85 \mathrm{v} \%$ and $8.60 \mathrm{v} \%$, respectively. The $\mathrm{Pu}$ vector is shown in Table 1.

Table 1. Pu vector

$\begin{array}{lr}\text { Isotope } & \text { Weight \% } \\ \mathrm{Pu}-238 & 2.5 \\ \mathrm{Pu}-239 & 54.3 \\ \mathrm{Pu}-240 & 23.8 \\ \mathrm{Pu}-241 & 12.6 \\ \mathrm{Pu}-242 & 6.8\end{array}$




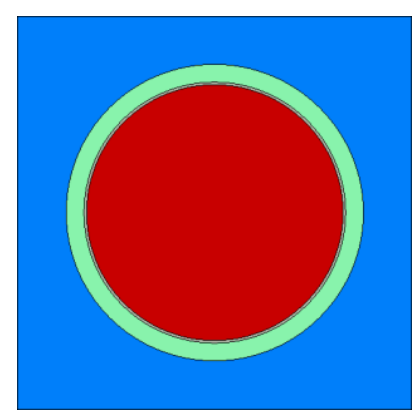

Fig. 1. PWR pin cell model

All three pin cells were depleted for 1300 days under nominal operating conditions:

- power density of $104 \mathrm{~W} / \mathrm{cm}^{3}$,

- coolant density of $0.713 \mathrm{~g} / \mathrm{cm}^{3}$,

- fuel temperature of $900 \mathrm{~K}$.

The decay heat power (as a fraction of nominal power) produced within 10 year after shutdown and partial contributions to it from actinides and fission products (FP) were calculated by Serpent and DYN3D and presented in Fig. 2. The deviation of DYN3D total decay heat results from those of Serpent is shown in Fig. 3. It is clear that DYN3D is able to accurately calculate the fuel nuclide content and thus decay heat production. However, some minor discrepancies exist primarily due to the fission yields which were kept fixed in DYN3D throughout the burnup.

The maximum difference in total decay heat power estimated by DYN3D and Serpent is less than $0.7 \%$, which is very good agreement considering typical nodal power errors in DYN3D are on the order of 1-3\% (Nikitin et al., 2015; Bilodid et al., 2018). 

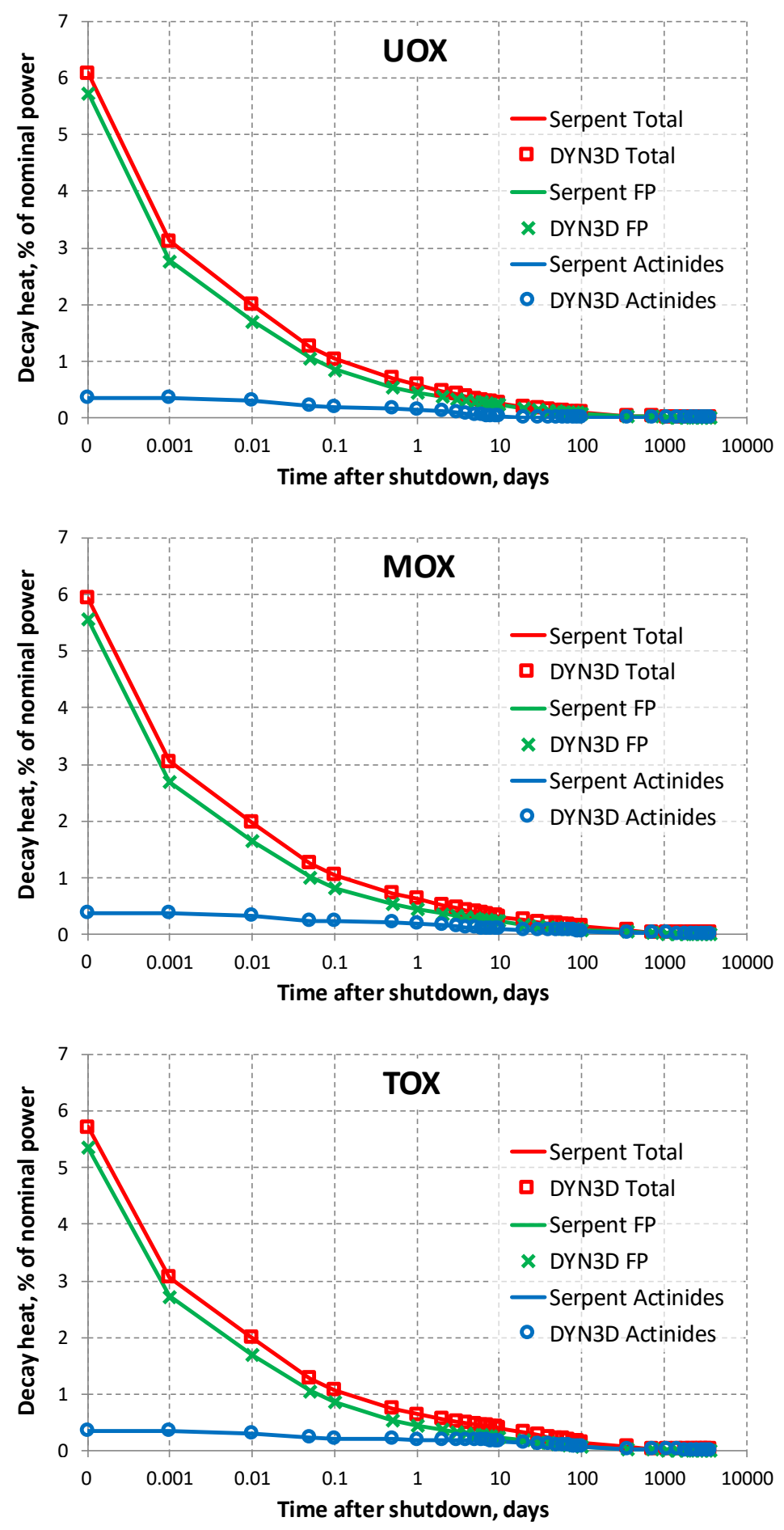

Fig. 2 Decay heat power after shutdown 


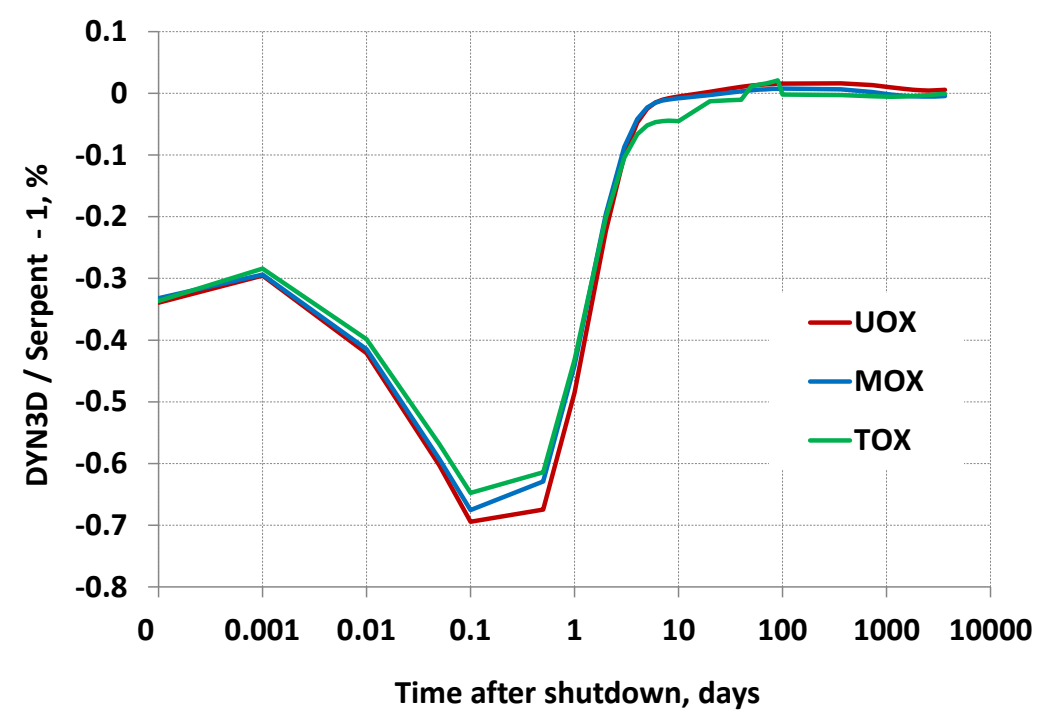

Fig. 3 Relative difference in decay heat power, DYN3D vs. Serpent

Fig. 4 compares decay heat generated by the three considered fuel types. At the nominal power level before shutdown, the contributions of radiative decay to total power calculated by Serpent for UOX, MOX and TOX fuels are $6.10 \%, 5.94 \%$ and $5.71 \%$, respectively. In the first period after shutdown up to one day, the decay powers of the three fuel types are practically equal. After about 1 day, the UOX fuel produces significantly less decay heat than MOX and TOX and the difference is growing with time.

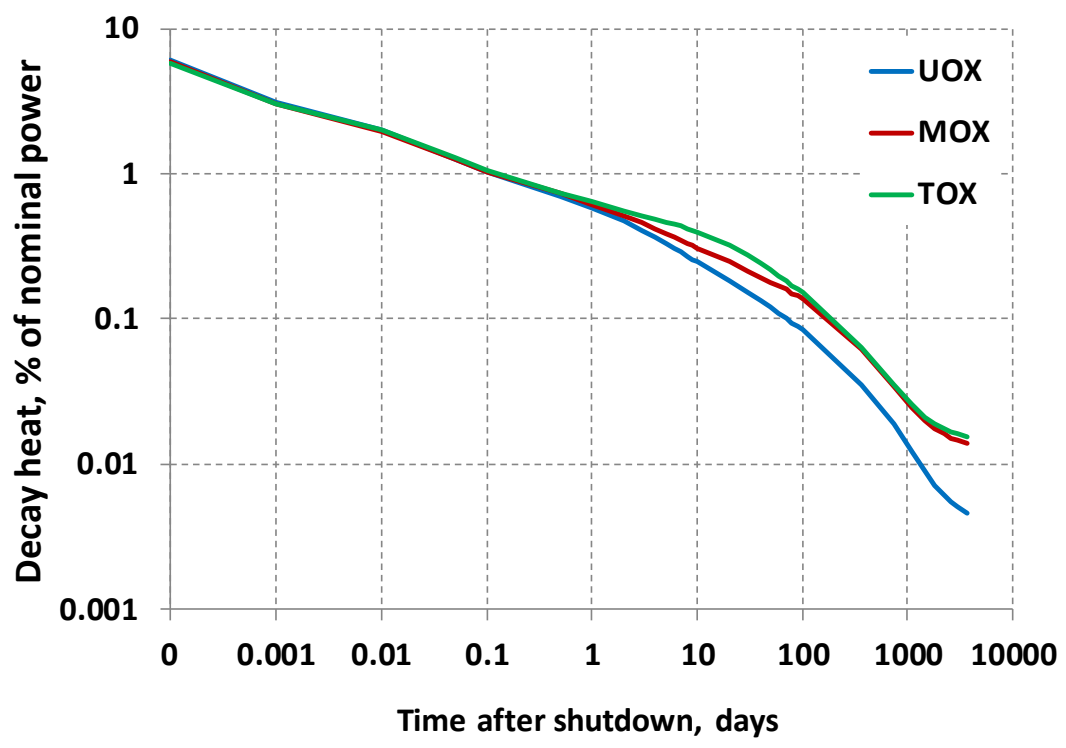

Fig. 4 Comparison of the decay heat form three fuel types 
Contributions of different nuclides to the decay heat power are shown in Fig. 5. The contributions of five nuclides which contribute the most to the decay heat at 0.001 days (86 seconds) and 365 days (1 year) after shutdown are shown for the three considered fuel materials in short and long time scales.

In the first minutes after shutdown, the decay heat is dominated by a range of short living nuclides, each with a relatively small contribution. At 0.001 days after shutdown, the five shown nuclides cumulatively produce less than $20 \%$ of the total decay heat. The biggest contributors to the UOX and MOX decay heat are U-239 and Np-329, which are produced by neutron capture in U-238 and successive beta-decay, respectively. Due to the absence of U238 in the fresh TOX fuel, these two nuclides have negligible contributions to decay heat of TOX and their roles are replaced by Th-233 and Pa-233. The contributions of the three most important short-lived fission products Cs-138, I-134 and La-140 are quite similar for all fuel materials.

At 1 year after shutdown, the five shown nuclides cumulatively produce about $80 \%$ of the total decay heat. The total decay heat of MOX and TOX at this time point are very similar to each other and significantly higher than the decay heat of UOX. Similarly, the decay heat components of MOX and TOX are also very similar to each other, while both differ from UOX. For all three fuel materials, the long lived fission products Rh-106 and Pr-144 are important contributors to the decay heat. The main difference between UOX and plutonium-containing MOX and TOX is significant contribution of minor actinides Cm-242 and Cm-244. Higher concentration of these heavy actinides before shutdown is explained by the presence of plutonium in MOX and TOX initial compositions. The higher concentration of Y-90 in UOX fuel is explained by the higher fission yield of Y-90 in fissions of U-235 than in Pu isotopes.

Fig. 6 shows the decay of selected nuclides with significant contribution to the decay heat generated by the three depleted materials. For the shown nuclides, the deviation of nuclide densities calculated by DYN3D from those calculated in Serpent are less than $0.1 \%$. 

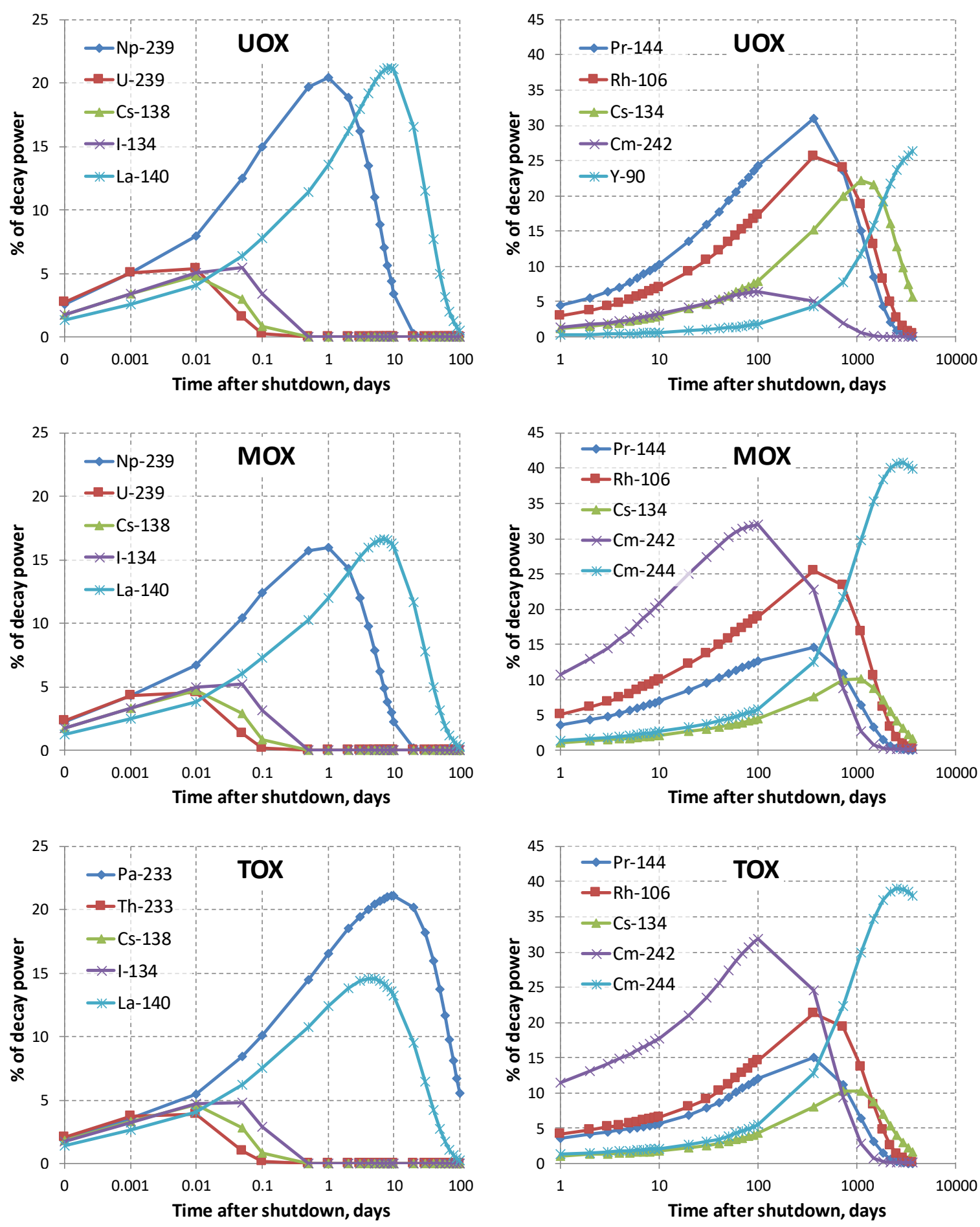

Fig. 5 Nuclides contributions to decay heat 

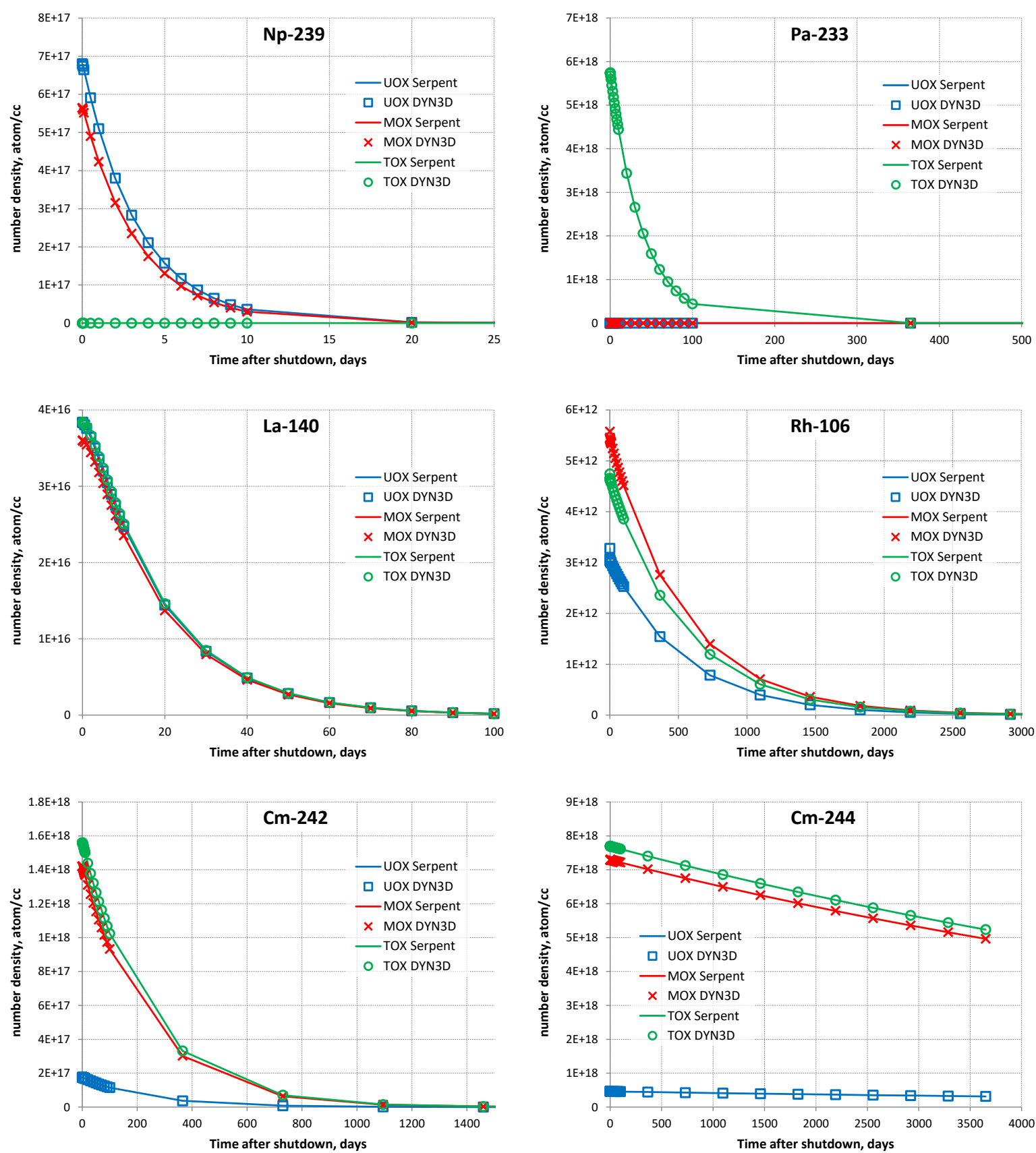

Fig. 6 Comparison of the nuclide content, DYN3D vs. Serpent

\subsection{PWR MOX pin cell in varying depletion conditions}

To demonstrate the ability of DYN3D to simulate an actual depletion history, the fuel depletion with varying operational parameters was simulated. The MOX fuel pin was depleted in 3 sequential burnup periods of 300 days, each followed by a 60 -day shutdown interval. The decay heat was then calculated over a period of 10 years after the last burnup cycle. The power history and variation of coolant density is shown in Fig. 7 (top). DYN3D depletion calculations 
were performed employing the pre-generated macro- and microscopic XS corrected using the hybrid micro-depletion method (Bilodid et al., 2016).

The results obtained with Serpent and DYN3D are compared in Fig. 7 and Fig. 8 and generally exhibit satisfactory agreement. During the first two burnup periods (up to 720 days), the difference in k-inf values calculated by Serpent and DYN3D stayed well within about 100 pcm (Fig. 7, middle). For the third burnup period, the difference in k-inf somewhat increased due to accumulation of error in the nuclide content. However, it did not exceed $200 \mathrm{pcm}$.

Decay heat predicted by Serpent and DYN3D for the 3 burnup periods including shutdown intervals and for the 10-year period following the shutdown are shown in Fig. 7 (bottom) and Fig. 8 respectively. In both cases, the maximum difference between the DYN3D and Serpent results is less than $1 \%$. 


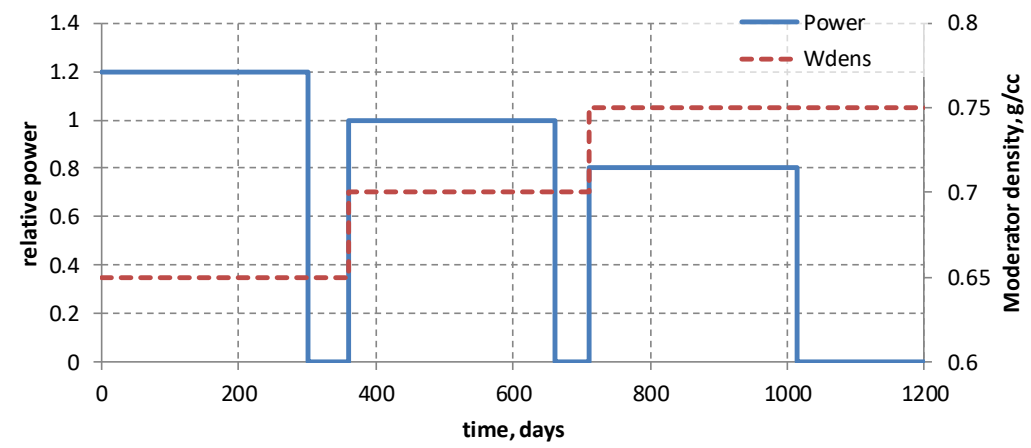

(a) Power and moderator density histories

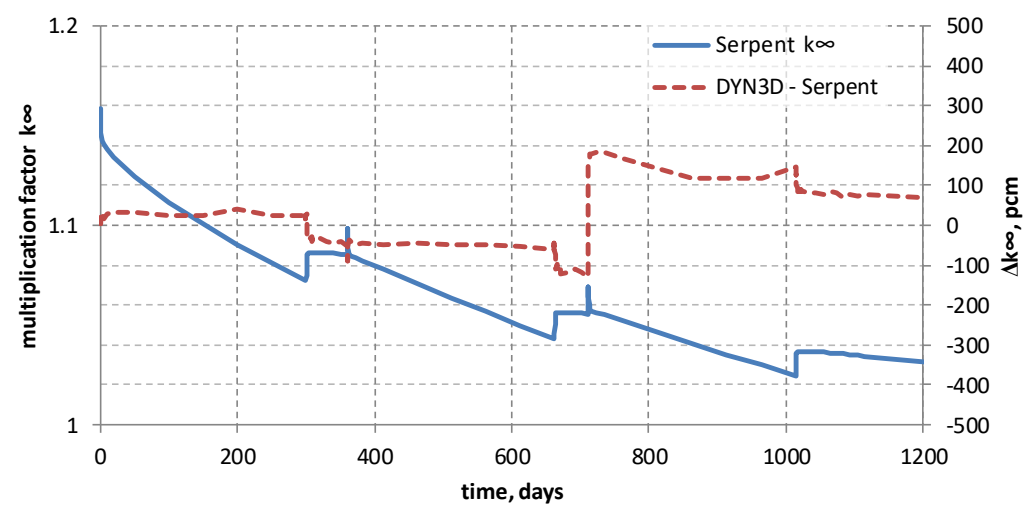

(b) Serpent and DYN3D $\mathrm{k}_{\infty}$ results

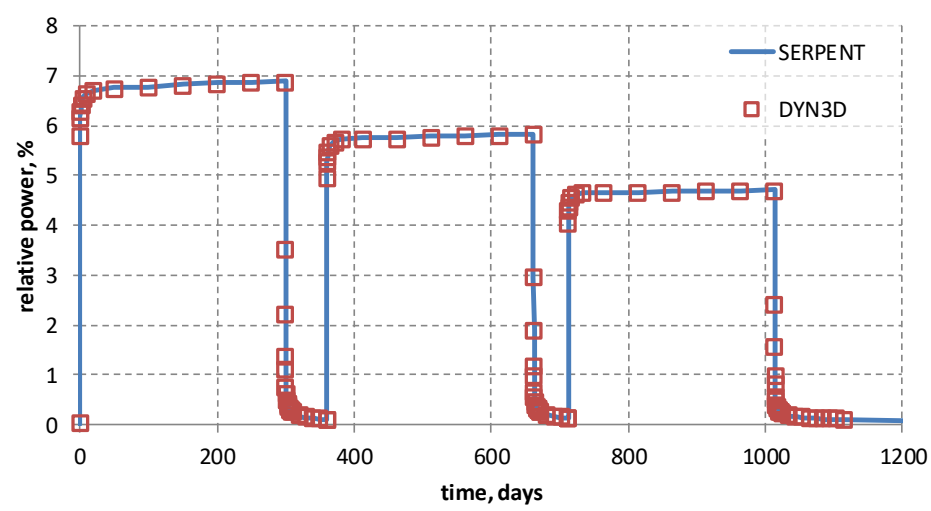

(c) Serpent and DYN3D decay heat results

Fig. 7 Depletion in varying conditions 


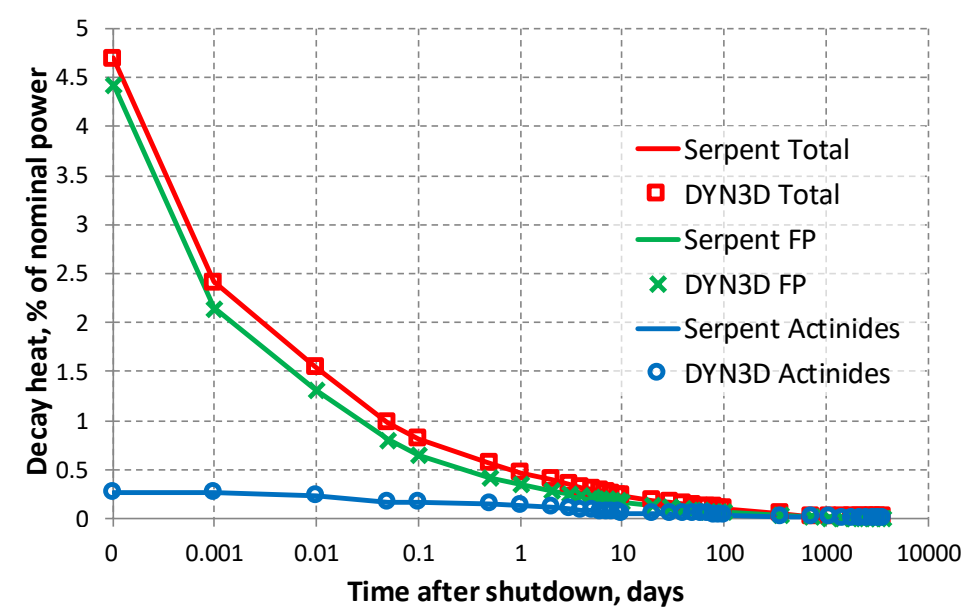

Fig. 8 Decay heat after shutdown.

\subsection{SFR MOX subassembly}

Since the implemented method is explicit and general, it could be applied not only to LWRs but also to fast spectrum systems. This has been demonstrated on a sodium fast reactor (SFR) MOX subassembly test case. The subassembly model contains 271 fuel pins in a steel shroud and modelled with reflective boundary conditions. The fuel material in all pins is uranium-plutonium mixed oxide with heavy metal composition shown in Table 2.

Table 2 SFR MOX fuel composition

$\begin{array}{lr}\text { Isotope } & \text { Weight \% } \\ \mathrm{U}-235 & 0.21 \\ \mathrm{U}-238 & 85.28 \\ \mathrm{Pu}-238 & 0.52 \\ \mathrm{Pu}-239 & 6.88 \\ \mathrm{Pu}-240 & 4.30 \\ \mathrm{Pu}-241 & 1.19 \\ \mathrm{Pu}-242 & 1.51 \\ \mathrm{Am}-241 & 0.11\end{array}$

The applied depletion conditions were:

- power density of $206 \mathrm{~W} / \mathrm{cm}^{3}$,

- sodium density of $0.85 \mathrm{~g} / \mathrm{cm}^{3}$,

- fuel temperature of $1200 \mathrm{~K}$. 


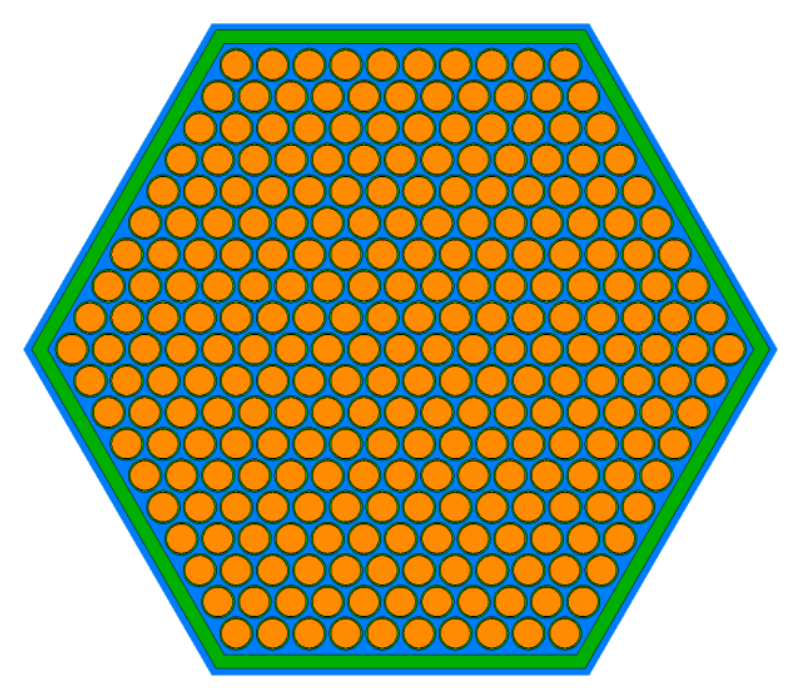

Fig. 9 SFR subassembly model

The assembly burnup was modeled for 1300 days and 10 years of subsequent cooling period in Serpent and DYN3D. The results of decay heat and its components calculated by DYN3D and Serpent are shown in Fig. 10. In this test case, the DYN3D results are very closely agree with those of Serpent with deviations of less than $0.05 \%$.

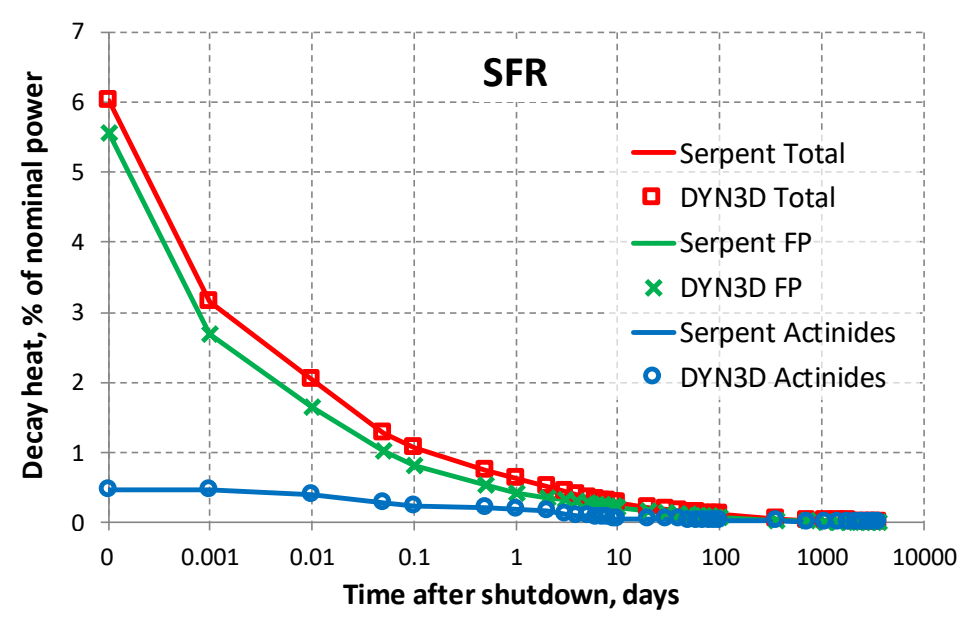

Fig. 10 Decay heat after shutdown.

\subsection{VVER fuel assembly with Gd burnable absorber}

To demonstrate the applicability of the proposed method to realistic heterogeneous fuel designs, a fuel assembly of VVER reactor (PWR with hexagonal lattice) is considered. The fuel material is uranium dioxide. The enrichment of pins in the central assembly zone is $4 \mathrm{w} \%$ of $\mathrm{U}-235$ and that of periphery pins is $3.6 \mathrm{w} \%$. Six burnable absorber pins contained a mixture 
of $3.3 \mathrm{w} \%$ enriched UOX with $5 \mathrm{w} \%$ of $\mathrm{Gd}_{2} \mathrm{O}_{3}$. The 2-dimensional assembly model is shown in Fig. 11. Reflective boundary conditions are applied on all faces of the assembly.

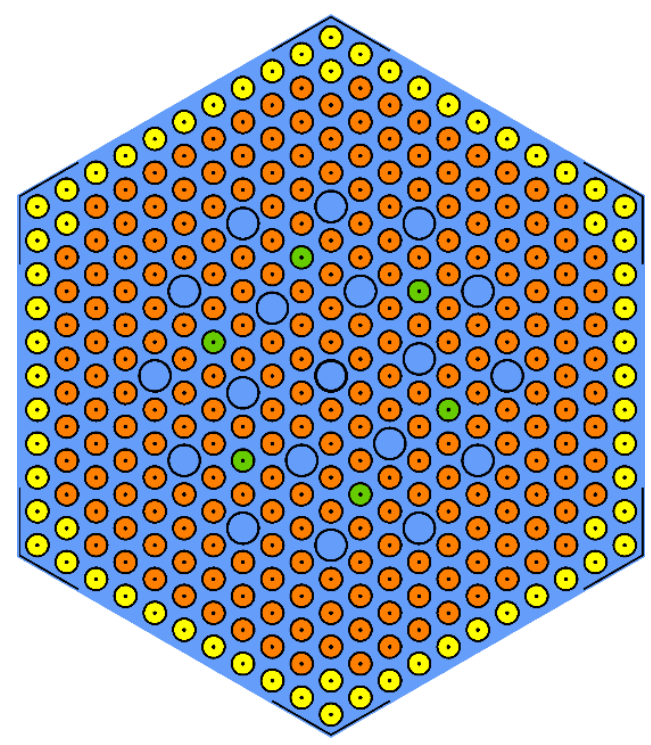

Fig. 11 VVER fuel assembly model

The fuel assembly depletion at constant operating conditions was modeled in Serpent and DYN3D for 1300 days and the decay heat was calculated for the following 10 years cooling period. The applied depletion conditions were:

- power density of $107 \mathrm{~W} / \mathrm{cm}^{3}$,

- coolant density of $0.713 \mathrm{~g} / \mathrm{cm}^{3}$,

- fuel temperature of $900 \mathrm{~K}$.

The comparison of decay heat calculated by DYN3D and Serpent is shown in Fig. 12. The maximum deviation of DYN3D results from Serpent is $0.7 \%$. 


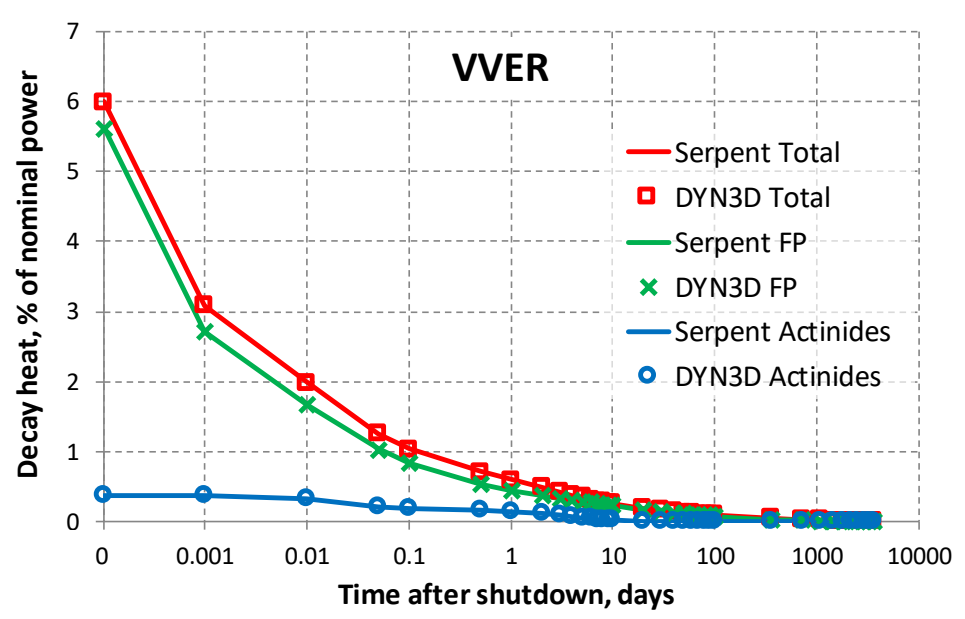

Fig. 12 Decay heat after shutdown.

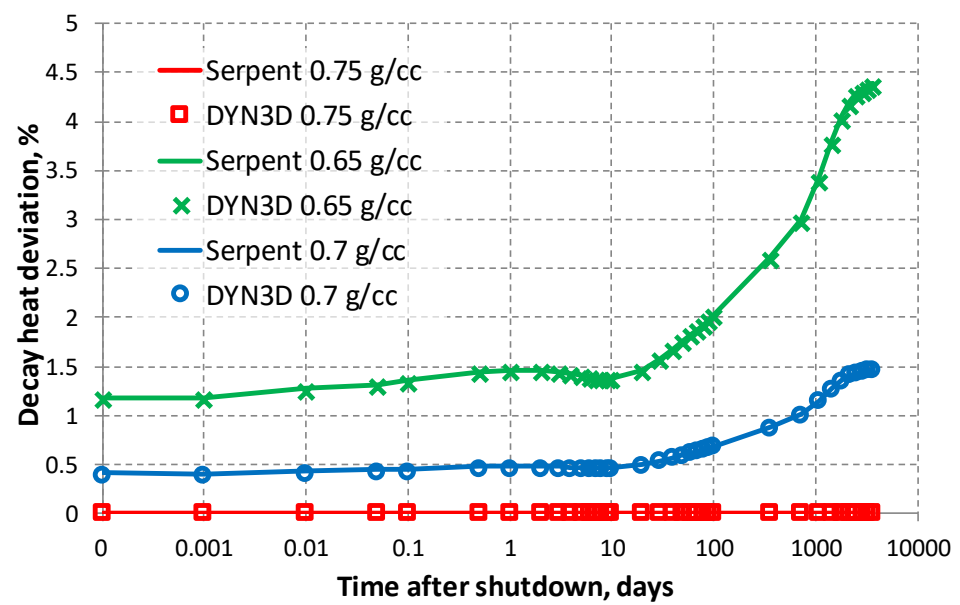

Fig. 13 Decay heat power dependence on depletion conditions.

The nuclide content in the depleted fuel and the decay heat depend not only on the accumulated burnup but also on operating conditions during the burnup. The traditional decay heat estimation approach based on the standard curves involves approximations to account for fuel burnup, but ignores the actual operational history and conditions. To demonstrate the effect of operation history, the fuel assembly depletion was repeated twice with the same operating conditions, but different water density of $0.75 \mathrm{~g} / \mathrm{cm}^{3}$ and $0.65 \mathrm{~g} / \mathrm{cm}^{3}$, which approximate the core inlet and outlet conditions, respectively.

The difference between the decay heat produced by the studied VVER fuel assembly model with the same burnup but different water density history is shown in Fig. 13. The depletion with core inlet and outlet coolant density results in about $1-1.5 \%$ difference in the decay heat in the initial few hours and up to $4.5 \%$ in longer time scale. In all cases, DYN3D accurately reproduces Serpent results. 


\section{Summary and conclusions}

This paper presented a method for decay heat calculation which was recently implemented in 3D nodal reactor dynamic code DYN3D. The method explicitly accounts for the heat from the decay of each nuclide in the fuel. Detailed nuclide content, required for the decay heat estimation, is calculated by DYN3D using recently implemented micro-depletion solver, while taking into account the local operational history of each node.

The presented method is more computationally expensive than methods based on the decay heat standards, but it is based on "first principles", does not involve any assumptions about the fuel content or operational history and, therefore, its applicability is not restricted to any particular fuel type. It is important to emphasize that high fidelity decay heat calculations typically require coupled Monte Carlo depletion codes (e.g. Serpent), which are computationally expensive because they require multiple neutron transport solutions. In this work however, the transport solution is replaced by a computationally efficient multi-group diffusion solution that allows predicting the 3-dimensional decay heat generation with only modest computational requirements.

The presented method was applied to a number of $2 \mathrm{D}$ infinite lattice test cases with thermal spectrum PWR UOX, MOX and TOX fuel, VVER UOX fuel with burnable absorber as well as fast spectrum SFR MOX fuel and was verified against reference Serpent 2 MC solutions. The test cases have demonstrated a notable dependence of the decay heat on the fuel initial composition and burnup operational history. In all test cases, the deviation of DYN3D decay heat from Serpent 2 reference stayed within 1\%. This indicates that DYN3D is able to accurately estimate the decay heat power distribution during burnup and shutdown periods for a wide range of reactor systems.

Future work will be focused on testing the method in realistic full core cases as well as depletion system compression and performance optimization. 


\section{References}

ANSI/ANS-5.1-, 2005. Decay Heat Power in Light Water Reactors.

Austregesilo, H.; Bals, C.; Hora, A.; Lerchl, G.; Romstedt, P., 2006. ATHLET, Mod 2.1 Cycle A, Models and Methods, GRS - P - 1 / Vol. 4, Gesellschaft für Anlagen- und Reaktorsicherheit (GRS) mbH, Germany.

Becker, A., Anton, G., Børresen, S., 2009. SNF: Spent fuel analyses based on casmo/simulate in-core fuel management, in: American Nuclear Society - 4th Topical Meeting on Advances in Nuclear Fuel Management 2009, ANFM IV.

Bilodid, Y., Grundmann, U., Kliem, S., 2018. The HEXNEM3 nodal flux expansion method for the hexagonal geometry in the code DYN3D. Annals of Nuclear Energy 116, pp. 187194.

Bilodid, Y., Kotlyar, D., Shwageraus, E., Fridman, E., Kliem, S., 2016. Hybrid microscopic depletion model in nodal code DYN3D. Annals of Nuclear Energy 92, pp. 397-406.

Børresen, S., Becker, A., Anton, G., Simeonov, T., 2008. Multi-Dimensional Methods for Back-End and Decay Heat Calculations of BWR, PWR and WWER Fuel Assemblies, in: International Conference on WWER Fuel Performance, Modelling and Experimental Support, Albena (Bulgaria).

DIN Norm 25463, 1990. Berechnung der Nachzerfallsleistung der Kernbrennstoffe von Leichtwasserreaktoren.

Downar, T., Xu, Y., Seker, V., 2010. PARCS v3.0 U.S. NRC Core Neutronics Simulator USER MANUAL.

Fridman, E., Kliem, S., 2011. Pu recycling in a full Th-MOX PWR core. Part I: Steady state analysis. Nuclear Engineering and Design 241, pp. 193-202.

Gauld, I.C., Radulescu, G., Ilas, G., Murphy, B.D., Williams, M.L., Wiarda, D., 2011. Isotopic Depletion and Decay Methods and Analysis Capabilities in SCALE. Nuclear Technology 174, pp. 169-195.

Grundmann, U., Lucas, D., Rohde, U., 1995. Coupling of the thermohydraulic code ATHLET with the neutron kinetic core model DYN3D., in: Int. Conf. on Mathematics and Computations, Physics and Environmental Analysis, Vol. 1. 
Grundmann, U., Rohde, U., Mittag, S., Kliem, S., 2005. DYN3D version 3.2 - code for calculation of transients in light water reactors (LWR) with hexagonal or quadratic fuel elements - description of models and methods. HZDR, FZR-434, Dresden, Germany.

Huang, K., Wu, H., Li, Y., Cao, L., 2017. Depletion system compression method with treatment of decay heat. Progress in Nuclear Energy 101, pp. 476-485.

Ilas, G., Gauld, I.C., Liljenfeldt, H., 2014. Validation of ORIGEN for LWR used fuel decay heat analysis with SCALE. Nuclear Engineering and Design 273, pp. 58-67.

INL, 1998. RELAP5/MOD3.2.2 Code Manual.

ISO 10645:, 1992. Nuclear energy -- Light water reactors -- Calculation of the decay heat power in nuclear fuels.

Kozmenkov, Y., Orekhov, Y., Grundmann, U., Kliem, S., Rohde, U., Seidel, A., 2001. Development and benchmarking of the DYN3D/RELAP5 code system, in: Annual Meeting on Nuclear Technology.

Leppänen, J., Pusa, M., Fridman, E., 2016. Overview of methodology for spatial homogenization in the Serpent 2 Monte Carlo code. Annals of Nuclear Energy 96, pp. $126-136$.

Leppänen, J., Pusa, M., Viitanen, T., Valtavirta, V., Kaltiaisenaho, T., 2015. The Serpent Monte Carlo code: Status, development and applications in 2013. Annals of Nuclear Energy 82, pp. 142-150.

Nikitin, E., Fridman, E., Mikityuk, K., 2015. On the use of the SPH method in nodal diffusion analyses of SFR cores. Annals of Nuclear Energy 85, pp. 544-551.

Pusa, M., 2011. Rational approximations to the matrix exponential in burnup calculations. Nuclear Science and Engineering 169, pp. 155-167.

Pusa, M., Leppänen, J., 2010. Computing the Matrix Exponential in Burnup Calculations. Nuclear Science and Engineering 164, pp. 140-150.

Rhodes, J., Smith, K., Lee, D., 2006. CASMO-5 Development and Applications 2 . CASMO5 Description and Development. Physicspp. 1-11.

Rohde, U., Kliem, S., Grundmann, U., Baier, S., Bilodid, Y., Duerigen, S., Fridman, E., Gommlich, A., Grahn, A., Holt, L., Kozmenkov, Y., Mittag, S., 2016. The reactor dynamics code DYN3D - Models, validation and applications. Progress in Nuclear Energy 
89, pp. $170-190$.

Shwageraus, E., Hejzlar, P., 2009. Decay heat in fast reactors with transuranic fuels. Nuclear Engineering and Design 239, pp. 2646-2653.

Sollima, C., Petrangeli, G., 2008. Decay heat issues for best estimate models, in: International Conference on Nuclear Engineering, Proceedings, ICONE.

Tobias, A., 1980. Decay heat. Progress in Nuclear Energy 5, pp. 1-93.

Wemple, C.A., Simeonov, T., Rhodes, J.D., 2017. HELIOS-2 Methods Manual. 